\title{
Infection patterns in White Sea blue mussels Mytilus edulis of different age and size with metacercariae of Himasthla elongata (Echinostomatidae) and Cercaria parvicaudata (Renicolidae)
}

\author{
K. E. Nikolaev, A. A. Sukhotin, K. V. Galaktionov* \\ Zoological Institute of the Russian Academy of Sciences, White Sea Biological Station, Universitetskaja Naberezhnaja 1, \\ 199034 St. Petersburg, Russia
}

\begin{abstract}
Infection of mussels Mytilus edulis L. by 2 trematode species was studied in a natural intertidal population in the Chupa inlet of the White Sea. The prevalence of metacercariae of Himasthla elongata (Mehlis, 1831) and Cercaria parvicaudata (Stunkard \& Shaw, 1931) in mussels reached $100 \%$ in 3 to 4 yr old molluscs and remained at this level in older individuals. Infection intensity increased evenly with the age of the molluscan host, showing a tendency to decrease only in the oldest (9 yr old) mussels. These patterns of age dynamics of prevalence and infection intensity were associated with accumulation of trematode larvae in the course of the molluscs' lives. Ability of metacercariae to exist in mussels for long periods (at least $2.5 \mathrm{yr}$ ) was verified in the course of an experiment, during which infected molluscs were kept in a subtidal net cage. Decrease of infection intensity in the oldest individuals may reflect selective mortality of the most severely infected molluscs. Among mussels of the same age, higher infection intensity values occurred in larger individuals. This may be due to an enhanced pumping rate in large molluscs, which increases the probability of cercariae, free-living trematode larvae, infecting them via water currents.
\end{abstract}

KEY WORDS: Mussels $\cdot$ Metacercariae $\cdot$ Digenea $\cdot$ Age $\cdot$ Size $\cdot$ Himasthla elongata $\cdot$ Cercaria parvicaudata $\cdot$ White Sea

\section{INTRODUCTION}

Trematode metacercariae parasitizing bivalve molluscs may influence vital functions of the hosts, lowering their resistance to unfavourable environmental factors and, in the case of intensive infection, even causing their death and resulting in mass mortality (Lauckner 1971, 1983, 1987, Bartoli 1974, James et al. 1977). Therefore, studies on bivalve-metacercariae interaction are very important, especially when applied to common and commercially important molluscan species. The blue mussel Mytilus edulis L. is one of the main components of intertidal and upper subtidal communities in the White Sea as well as being the object of an aquaculture industry in this region (Lukanin 1985, Sukhotin 1993). Five trematode species have been reported from White Sea mussels; 2 of them, Himasthla elongata (Mehlis, 1831) (Echinostomatidae) and Cercaria parvicaudata Stunkard \& Shaw, 1931 (Renicolidae), are the most common in molluscs inhabiting the intertidal zone (Chubrick 1966, Zelikman 1966, Kulatchkova 1985, 1987, Galaktionov 2001). Mussels are the second intermediate host for these 2 species of trematode, the first intermediate host being intertidal snails Littorina spp., and the final hosts being various species of marine and coastal birds such as gulls and waders.

The present work analyses the differential effects of host age and size on infection indices in mussels infected with Himasthla elongata and Cercaria parvicaudata metacercariae. Increase in prevalence and infection intensity with age and/or size of animal hosts 
is a well-established concept of ecological parasitology (Dogiel 1964, Kennedy 1975). Coincidentally, size and age are closely correlated in animals with asymptotic growth, including bivalve molluscs (Alimov 1981). Therefore, a change in physiological functions in the ontogenesis and, consequently, a change in infection indices could be due to an increase in size (linear size, volume, weight) of the organism, or an increase in age (i.e. ageing), or a joint impact of these 2 factors. Usually it is almost impossible to determine how these factors interact. However, in the White Sea intertidal zone, Mytilus edulis are exceedingly variable with regards to their growth rate (Savilov 1953, Sukhotin \& Maximovich 1994). Molluscs in the 4 to 6 age groups may fall into the same size class, whereas mussels of the same age may differ in size significantly. This makes it possible to perform a differential analysis of the influence of mussel size and age upon changes in indices of infection with trematode metacercariae.

\section{MATERIALS AND METHODS}

Sampling. Blue mussels Mytilus edulis L. were collected in the intertidal zone of the cape dividing the Kruglaya and Seldyanaya creeks of the Chupa inlet $\left(66^{\circ} 20^{\prime} \mathrm{N}, 33^{\circ} 40^{\prime} \mathrm{E}\right.$, Kandalaksha Bay, White Sea). This area of the White Sea is characterised by quite strong seasonal fluctuations in temperature and salinity. Throughout the year the temperature of the surface water fluctuates from -0.8 to $13.5^{\circ} \mathrm{C}$, and the average salinity from 26.2 to $14.5 \%$ (Babkov 1998). Maximal tide amplitude is 2.0 to $2.1 \mathrm{~m}$. The collection site was a rocky intertidal zone, with inclusions of pebbly-sandy areas. The lower and middle levels were densely covered with fucoids, mostly Fucus vesiculosus and Ascophyllum nodosum. Periwinkles Littorina saxatilis and L. obtusata were abundant there, whereas L. littorea was very rare. Numerous mussels (Mytilus edulis) covered the lower parts of the stones or formed separate druses. Population density of the molluscs was $3605 \pm$ 21 ind. $\mathrm{m}^{-2}$ (mussels with shell length exceeding $5 \mathrm{~mm}$ and of age 1 to $9 \mathrm{yr}$ were considered).

Mussel samples (50 to 70 ind. per sample) were collected within the zone of fucoids in November 1999, March, August and November 2000, March and August 2001. The shell length of each mollusc was measured to the nearest $0.1 \mathrm{~mm}$, and age was determined by counting lines of the winter growth stops on the shell. Only molluscs with shell length exceeding $5 \mathrm{~mm}$ were included in the analysis, because preliminary investigations demonstrated absence of metacercarial infection in juveniles younger than $1 \mathrm{yr}$. Mussels were dissected, their soft tissues squeezed between 2 slides and viewed under a stereomicroscope. The num- ber of metacercariae of Himasthla elongata and Cercaria parvicaudata localised in different mussel organs were counted. In metacercariae of $C$. parvicaudata 4 age groups were recorded, distinguished by their excretory bladder shape and the degree to which it was filled with excretory granules

- Young metacercariae (YM): a Y-shaped bladder that did not contain excretory granules

- Fully formed metacercariae (FFM): a bladder of regular Y-shape containing some excretory granules

- Old metacercariae (OM): a bladder of irregular shape occupying most of the metacercarial body and filled with numerous excretory granules

- Dead metacercariae (DM) in various stages of decomposition.

As the number of DM was small, they were not included in further analysis. We could not distinguish clear age groups in Himasthla elongata metacercariae.

Analysis. When calculating parameters of mussel infection with metacercariae, combined data from all samples were used. Prevalence $(P)$ was calculated as the percentage of molluscs infected with a particular metacercarial species, and infection intensity (IIn) as the number of metacercariae of a particular species in an infected mollusc.

When determining $P$ with metacercariae in mussels of various sizes, 8 size (shell length) classes of molluscs were distinguished: I: $4.0-9.0$ mm; II: $9.1-13.0 \mathrm{~mm}^{\text {III: }}$ 13.1-17.0 mm; IV: $17.1-21.0 \mathrm{~mm}_{\text {; }} \mathrm{V}: 21.1-25.0 \mathrm{~mm}$; VI: 25.1-29.0 mm; VII: 29.1-33.0 mm; VIII: $33.1-37.0 \mathrm{~mm}$. Mussel size effect on IIn was estimated by standard algorithms of regression and correlation analyses. Statistical significance of age influence upon IIn was determined using 1-way ANOVA (Underwood 1981). Post-hoc comparisons of IIn in mussels of different ages were performed with Tukey's test for unequal N. In some cases, Student's $t$-test was used for pair-wise comparison of means. All calculations were performed with the use of Statistica 5.5 software package.

To assess separate effects of mussel age and size on IIn with metacercariae of Himasthla elongata and FFM of Cercaria parvicaudata, 3 age groups of molluscs were distinguished: $1-3,4-6$ and $7-9$ yr. For each age group linear regressions of IIn on mollusc size were computed. To assess the influence of age on the IIn of mussels with metacercariae, values of IIn from each mussel with $H$. elongata and $C$. parvicaudata larvae were corrected to the mean size of mussels in the sample (shell length $L=18 \mathrm{~mm}$ ) according to the formula $I I n_{\text {corr }}=I I n+b(18-L)$, where $I I n_{\text {corr }}$ and IIn are corrected and observed infection intensity in a mollusc, respectively, and $b$ is the slope in linear regression of IIn on mollusc size for the corresponding age group (Table 1). For all mean values in the text and graphs, SEs are given. 
Field experiment. To determine the life span of Himasthla elongata and Cercaria parvicaudata metacercariae, a field experiment was performed from December 2000 to August 2003. Mussels from artificial substrates of mariculture were used as initial material because no trematode infection was observed in them. Mussels are not infected in this habitat because cercariae shed by the intertidal snails Littorina spp. cannot reach mariculture substrates placed far from the shore (Fjälling et al. 1980, Kulatchkova 1985). To obtain cercariae, the first intermediate hosts of $H$. elongata and C. parvicaudata-periwinkles Littorina saxatilis and L. obtusata - were collected from the area of the intertidal zone where mussels were sampled. To distinguish between infected and non-infected snails, each individual was isolated in a dish and exposed to light for about $1 \mathrm{~h}$. Snails shedding $H$. elongata and $C$. parvicaudata cercariae were isolated and used subsequently as a source of cercariae. Mussels collected from the mariculture substrates were each placed into a $70 \mathrm{ml}$ vessel with seawater, and 10 to 15 cercariae of $H$. elongata or 30 to 35 cercariae of C. parvicaudata were added. Exposure time for molluscs was 8 to $10 \mathrm{~h}$. After infection mussels were moved to a net cage, which was placed at some distance from the shore at a depth of $8 \mathrm{~m}$. These conditions excluded the possibility of subsequent natural infection of experimental mussels. Once or twice a year (see Table 3), 6 to 7 molluscs were taken from the cage and examined for the presence of $H$. elongata and $C$. parvicaudata metacercariae by the same method as that used for mussels from natural settlement.

\section{RESULTS}

The metacercariae of Himasthla elongata in the mussels were always localised in foot tissues, whereas the larvae of Cercaria parvicaudata were found only in the liver. Average values of $\mathrm{P}$ for $H$. elongata and C. parvicaudata metacercariae in molluscs were very similar, $87.3 \pm 2.3 \%$ and $91.6 \pm 2.4 \%$, respectively. Average IIn with larvae of $C$. parvicaudata $(25.3 \pm 2.5)$ was much higher than that with $H$. elongata larvae $(7.5 \pm 0.6)(p<$ 0.05).

\section{Metacercarial infection and host size}

Both P and IIn of metacercariae of Himasthla elongata and Cercaria parvicaudata in mussels depended on mussel size. P of metacercariae of $H$. elongata in the smallest mussels was $53.2 \pm 5.6 \%$ and increased continuously with increasing host size, reaching 95 to $100 \%$ in large individuals (Fig. 1). The same tendency

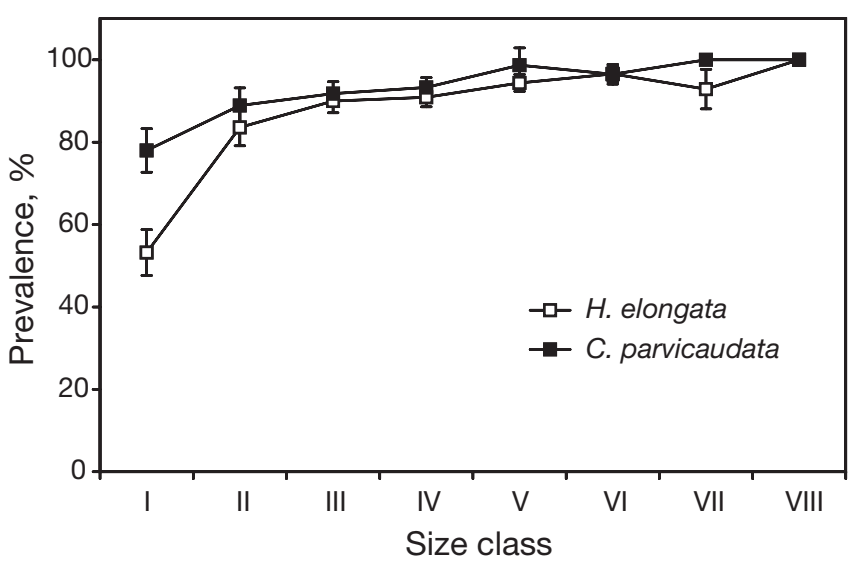

Fig. 1. Mytilus edulis. Prevalence of Himasthla elongata and Cercaria parvicaudata in mussels of different size

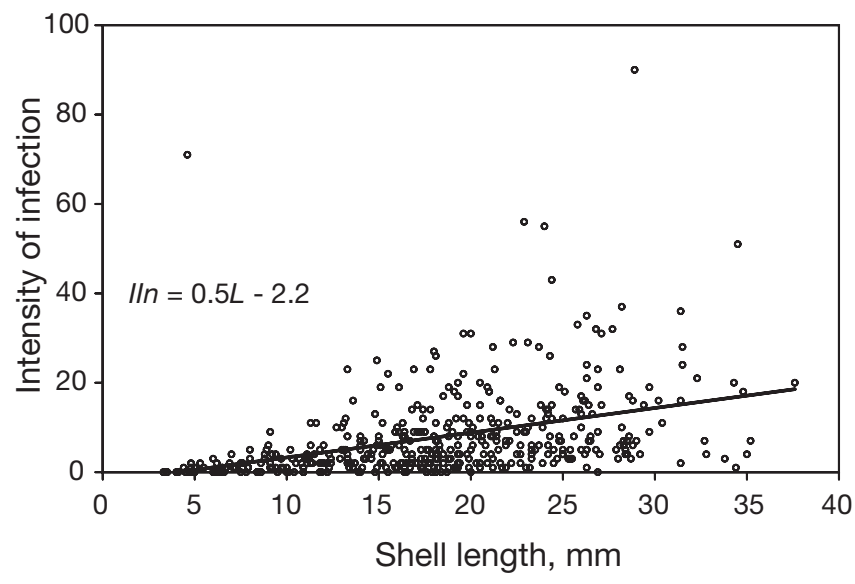

Fig. 2. Mytilus edulis. Intensity of infection (IIn) with Himasthla elongata metacercariae in mussels of different size $(L)$

was observed for $P$ of $C$. parvicaudata metacercariae in mussels (Fig. 1), $P$ in mussels in Size Class I reaching $78 \pm 5.3 \%$.

The IIn with Himasthla elongata metacercariae also increased significantly with increasing size of mussels $(\mathrm{R}=0.404, \mathrm{n}=455, \mathrm{p}<0.001$ ) (Fig. 2). Dependence of Cercaria parvicaudata IIn on host size differed in metacercariae of different age groups. In YM IIn was relatively constant, increasing slightly though significantly in the largest mussels ( $\mathrm{R}=0.197, \mathrm{n}=455, \mathrm{p}<$ 0.001) (Fig. 3A). The number of FFM per host specimen increased greatly with the host's increasing size, reaching more than 50 metacercariae per ind. in the largest mussels ( $\mathrm{R}=0.469, \mathrm{n}=455, \mathrm{p}<0.001$ ) (Fig. 3B). In comparison with the total number of larvae from other age groups, the number of OM was insignificant in mussels of all size classes (average IIn $1.4 \pm 0.2$ ), and grew slightly with increasing size of mussels $(\mathrm{R}=$ 0.299, $\mathrm{n}=455, \mathrm{p}<0.001$ ) (Fig. 3C). 

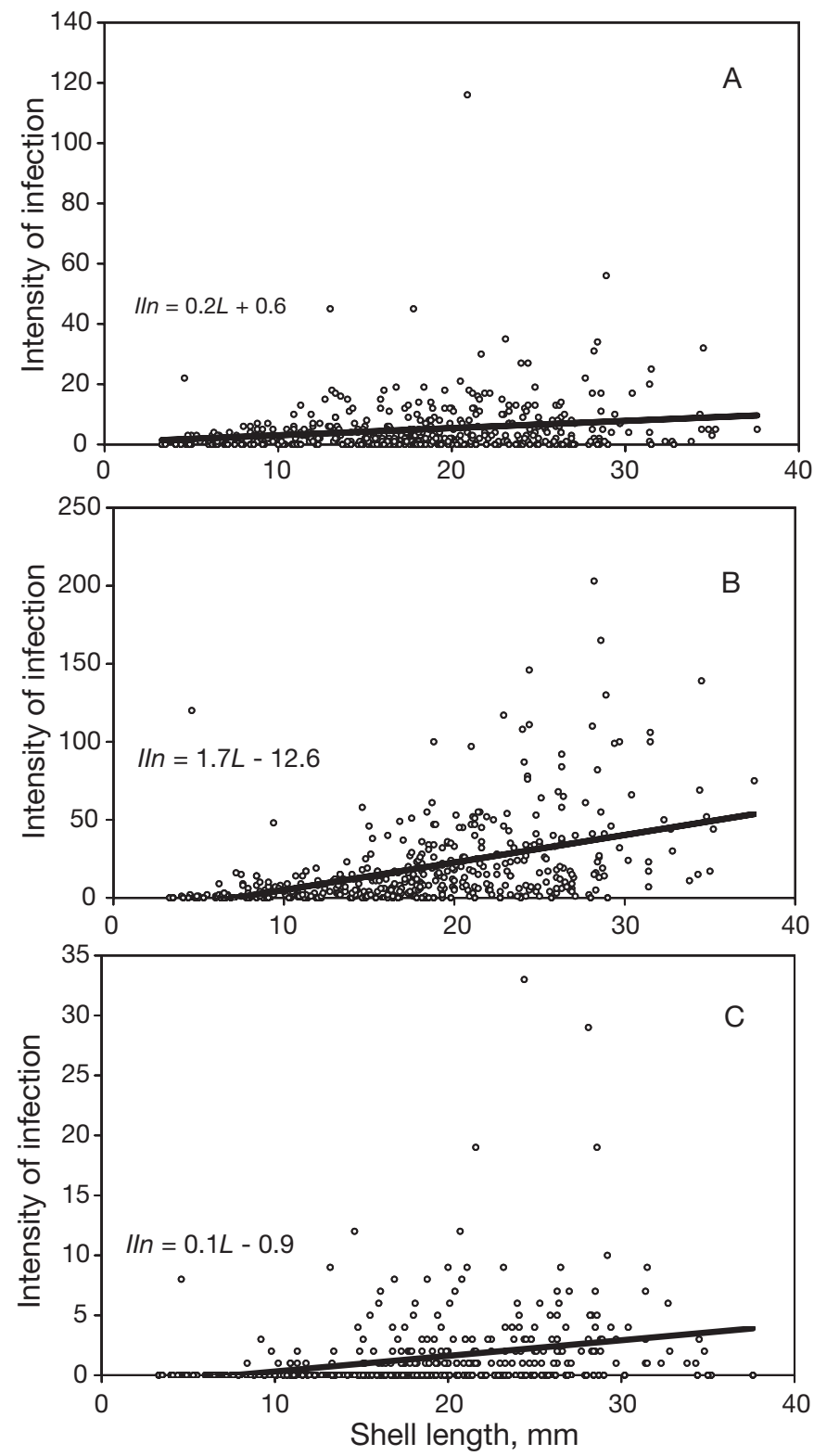

Fig. 3. Mytilus edulis. IIn with Cercaria parvicaudata metacercariae of different age groups of mussels of different size (L). (A) Young metacercariae (YM); (B) fully formed metacercariae $(\mathrm{FFM}) ;(\mathrm{C})$ old metacercariae $(\mathrm{OM})$

\section{Metacercarial infection and host age}

Dependence of $P$ of Himasthla elongata metacercariae on age of mussels was asymptotic (Fig. 4). As mussels aged, $P$ increased continuously, reaching $91.8 \pm 2.7 \%$ in $4 \mathrm{yr}$ old mussels and tending to level off afterwards (Fig. 4). Age dynamics of $P$ of Cercaria parvicaudata metacercariae in mussels was similar (Fig. 4). It is noteworthy that there was a decrease in $P$ in 2 yr old mussels as compared to 1 yr old ones ( $\mathrm{p}<$ 0.05, Tukey's HSD test). It was followed by an increase

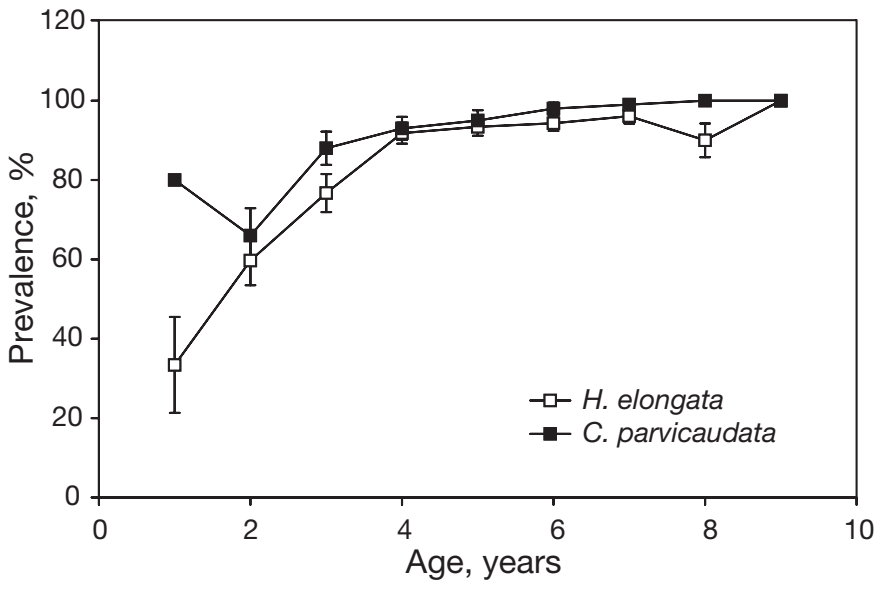

Fig. 4. Mytilus edulis. Prevalence of Himasthla elongata and Cercaria parvicaudata in mussels of different age

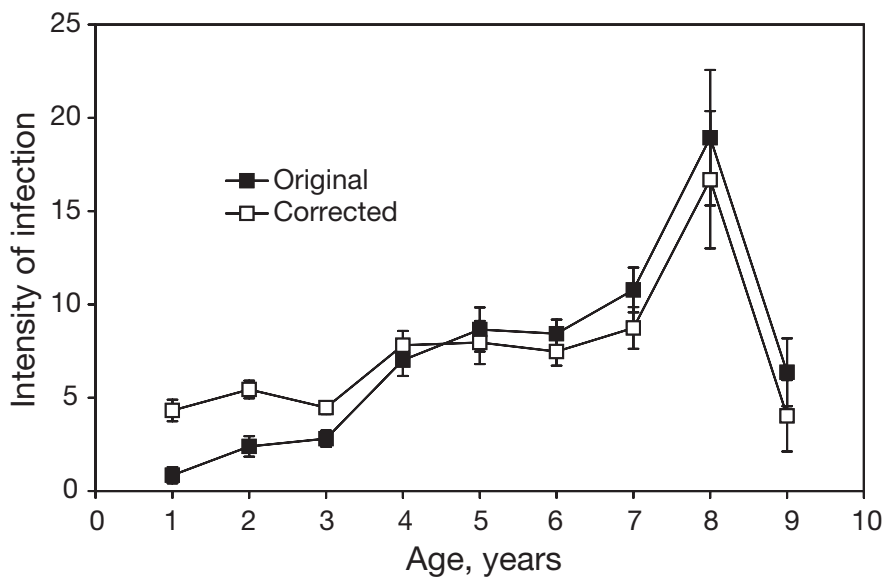

Fig. 5. Mytilus edulis. Original and size-corrected IIn with Himasthla elongata metacercariae in mussels of different ages

in $P$ up to $88 \pm 4.2 \%$ in $3 \mathrm{yr}$ old specimens. In older mussels, $\mathrm{P}$ did not vary significantly.

Mussel age considerably influenced IIn with metacercariae of Himasthla elongata (ANOVA, <0.001). With increasing host size, IIn increased from $0.8 \pm 0.3$ in $1 \mathrm{yr}$ old mussels to $10.7 \pm 1.0$ in $7 \mathrm{yr}$ and $18.9 \pm 2.5$ in 8 yr old mussels. However, in the oldest (9 yr old) mussels, the value of this index fell to $6.3 \pm 1.4(p=0.025$, Tukey's HSD test) (Fig. 5).

The host age effect on IIn with Cercaria parvicaudata larvae was similar among metacercariae of different age groups. IIn with YM was relatively low (4.9 \pm 0.4 ) and increased until the host reached 8 yr (ANOVA, $\mathrm{p}<0.01$ ). In $9 \mathrm{yr}$ old mussels an insignificant tendency for a decrease in IIn with YM was observed (Fig. 6); however, sample size (15 ind.) was too small for meaningful statistical analyses. The number of FFM increased with increasing age of the hosts (ANOVA, p < 


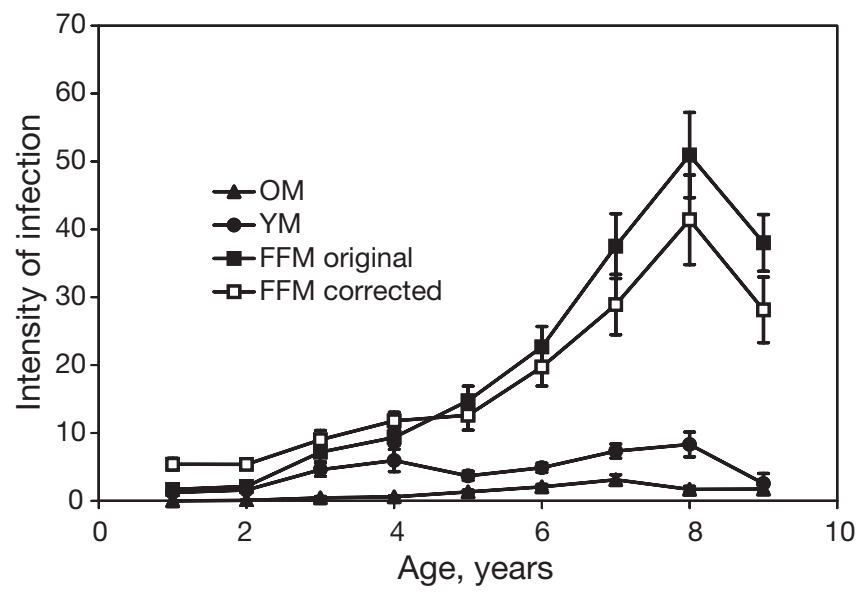

Fig. 6. Mytilus edulis. Original and size-corrected IIn with Cercaria parvicaudata OM, YM and FFM metacercariae in mussels of different ages. Size-corrected IIn with FFM also presented

0.001), reaching its maximum in $8 \mathrm{yr}$ old individuals (50.9 \pm 6.2 metacercariae per ind.). In 9 yr old mussels, an insignificant decrease in IIn with this age group of metacercariae was also observed. Although the number of OM was low, it also increased significantly from 0 in $1 \mathrm{yr}$ old mussels to $3.1 \pm 0.7$ in $7 \mathrm{yr}$ old mussels (ANOVA, $\mathrm{p}<0.01$ ), decreasing down to $1.6 \pm 0.4$ and $1.7 \pm 0.5$ in 8 and $9 \mathrm{yr}$ old individuals, respectively (Fig. 6).

\section{Differential influence of size and age of mussels on metacercarial infection}

Within each of the 3 mussel age groups, the influence of molluscan hosts age on IIn with metacercariae of Himasthla elongata and Cercaria parvicaudata was statistically significant (Table 1). The only exception was IIn with $H$. elongata larvae in the oldest age group of the mussels. An increase in IIn with increasing size of mussel was recorded in all age groups.

The effect of age on IIn of mussels corrected to average size $(18 \mathrm{~mm})$ with metacercariae of Himasthla elongata and FFM of Cercaria parvicaudata was significant (ANOVA, $\mathrm{p}<0.001$ for both trematode species) (Table 2, Figs. $5 \& 6$ ). An abrupt increase in IIn with age was observed in mussels older than 3 and 6 yr in the case of $H$. elongata infection, and in mussels older than $5 \mathrm{yr}$ in the case of $C$. parvicaudata infection.

\section{Results of the field experiment}

All control dissections of the experimentally infected mussels from the cage revealed the presence of
Table 1. Mytilus edulis. Influence of mussel host age on intensity of infection (IIn) with metacercariae of Himasthla elongata and Cercaria parvicaudata. Parameters of regression equation IIn $=a+b L$ for mussels of different age groups. $L$ : shell length of mussels (mm), $a$ and $b$ : coefficients of the regression equation, $\mathrm{R}$ : correlation coefficient, $\mathrm{N}$ : number of mussels analyzed

\begin{tabular}{|lccccc|}
\hline Mussel age & $a$ & $b$ & $\mathrm{R}$ & $\mathrm{p}$ & $\mathrm{N}$ \\
\hline H. elongata & & & & & \\
$1-3$ & -1.329 & 0.343 & 0.530 & $<0.001$ & 116 \\
$4-6$ & 0.155 & 0.421 & 0.285 & $<0.001$ & 232 \\
$7-9$ & 4.293 & 0.353 & 0.139 & $\mathrm{~ns}$ & 106 \\
FFM of $\boldsymbol{C}$. parvicaudata & & & & \\
$1-3$ & 0.604 & 0.365 & 0.231 & $<0.05$ & 116 \\
$4-6$ & -8.273 & 1.295 & 0.330 & $<0.001$ & 232 \\
$7-9$ & 5.714 & 1.493 & 0.233 & $<0.050$ & 106 \\
\hline
\end{tabular}

Table 2. Mytilus edulis. 1-way ANOVA results of influence of age on IIn of mussels with metacercariae of Himasthla elongata and Cercariae parvicaudata. IIn values were corrected for mean length of mussels (18 mm)

\begin{tabular}{|lrrrrr|}
\hline \multicolumn{2}{c}{ SS } & df & MS & F & p \\
\hline H. elongata & & & & & \\
Age & 3795.6 & 8 & 474.4 & 6.35 & 0.000 \\
Error & 33318.3 & 446 & 74.7 & & \\
FFM C. parvicaudata & & & & \\
Age & 45065.5 & 8 & 5633.2 & 11.37 & 0.000 \\
Error & 221063.1 & 446 & 495.7 & & \\
\hline
\end{tabular}

Table 3. Mytilus edulis. Mean number of metacercariae of Himasthla elongata and Cercaria parvicaudata in mussels that were experimentally infected in December 2000 and kept in subtidal cage

\begin{tabular}{|c|c|c|c|c|}
\hline \multirow{3}{*}{$\begin{array}{l}\text { Date of } \\
\text { observation }\end{array}$} & \multicolumn{4}{|c|}{ Mean number of metacercariae } \\
\hline & \multirow{2}{*}{ H. elongata } & \multicolumn{3}{|c|}{ C. parvicaudata } \\
\hline & & YM & FFM & OM \\
\hline 21 Mar 2001 & 9 & 1 & 25 & 0 \\
\hline 14 Aug 2001 & 8 & 0 & 32 & 0 \\
\hline 12 May 2002 & 7 & 0 & 15 & 0 \\
\hline 26 Aug 2002 & 10 & 0 & 29 & 0 \\
\hline 15 Aug 2003 & 8 & 0 & 22 & 1 \\
\hline
\end{tabular}

Himasthla elongata and Cercaria parvicaudata metacercariae in numbers comparable with the initial number of cercariae used for infection (Table 3). In the very first sample of mussels from the cage, taken 3 mo after the beginning of the experiment, all metacercariae of C. parvicaudata were at the FFM stage. In later samples, only accumulation of excretory granules in the bladder was observed. OM and DM were absent throughout the experiment (Table 3), and so were decomposing metacercariae of $H$. elongata. 


\section{DISCUSSION}

Almost all mussels in the studied settlement were infected with metacercariae of Himasthla elongata and Cercaria parvicaudata. This is typical for intertidal mussel settlements in the Kandalaksha and Onega Bays of the White Sea, which indicates that conditions for parasite transmission are favourable there $(\mathrm{Ku}-$ latchkova 1985, 1987, Galaktionov 2001, our unpubl. data). The P of rediae and sporocysts of C. parvicaudata in the first intermediate hosts, the periwinkles, at the sampling site of mussels was approximately the same throughout the investigation period, and did not exceed 1 to $2 \%$ (our unpubl. data). Therefore, a statistically significant higher IIn of mussels with metacercariae of C. parvicaudata cannot be explained by a higher prevalence of this species in the first intermediate hosts. It is very likely to be associated with much higher productivity of intramolluscan stages of C. parvicaudata compared with that of $H$. elongata. Average daily emission of $H$. elongata cercariae from infected Littorina littorea was $642 \pm 22$ (438 to 1002 ind.), and that of C. parvicaudata cercariae $2266 \pm 122$ (1053 to 3404 ind.), the larvae of the latter species retaining infectivity for a longer time (V. Prokofiev pers. comm.). Thus, even if IIn in the first intermediate hosts was the same, the average density of C. parvicaudata cercariae in a separate area of the intertidal zone turned out to be much higher than that of $H$. elongata cercariae. This increased the chances of the cercariae of the latter species infecting the second intermediate host, mussels.

The data obtained demonstrate a significant dependence of mussel infection with metacercariae of Himasthla elongata and Cercaria parvicaudata on age and size of the molluscan host. The growth of $P$ is observed only in younger mussels, whereas mussels older than 3 or 4 yr exhibit an almost $100 \% P$ of larvae of the 2 trematode species studied. At the same time, IIn increases evenly with increasing age of the molluscan host, tending to decrease only in the oldest individuals. These patterns of age dynamics of $P$ and IIn appear to be associated with accumulation of metacercariae throughout the mussel's life.

The life span of trematode metacercariae is very long. It reaches 7 to 8 mo in the larvae of Fasciolidae and Notocotylidae that encyst on submerged substrates, while the highly specialised metacercariae of Diplostomidae retain infectivity in the second intermediate host for up to 5 or 6 yr (Dönges 1969). According to our experiments, metacercariae of Himasthla elongata and Cercaria parvicaudata live for at least $3.5 \mathrm{yr}$, the larvae of $C$. parvicaudata not reaching the state of OM during this period. It would therefore seem that the life span of metacercariae of both trematode species is limited by that of infected mussels. This suppo- sition is supported, in particular, by the low number of $\mathrm{OM}$ and DM of $C$. parvicaudata in mussels of all ages. Dead metacercariae of Renicola roscovita and H. elongata in North Sea cockles were recorded by Lauckner (1983) mostly in spring. However, in that case, high mortality of metacercariae was not a result of the action of internal defence systems of molluscs; the larvae encysted in the tissue of palps died due to freezing.

High P of Cercaria parvicaudata metacercariae in mussels of age 1+ and its decrease in $2 \mathrm{yr}$ old mussels is likely caused by elimination of severely infected individuals under unfavourable conditions, e.g. in winter months. The most infected molluscs are the first to die. This premise is corroborated by the fact that IIn in $2 \mathrm{yr}$ and $1 \mathrm{yr}$ old mussels is almost the same, varying within the range of 1 to 2 . A similar pattern was described in juvenile Cerastoderma edule infected with metacercariae of Renicola roscovita and Himasthla elongata in the North Sea (Lauckner 1983). Most of the highly infected cockles of the 0-group died during their first winter, and the average IIn of the molluscs inspected in the following spring was lower than that of specimens settled in the previous autumn. Probably, at least in the White Sea, C. parvicaudata metacercariae are more pathogenic to young mussels than larvae of $H$. elongata, whose values of $P$ and IIn in mussels did not decrease in $2 \mathrm{yr}$ old individuals.

As well as in young specimens, a decrease in the IIn with metacercariae of Himasthla elongata and Cercaria parvicaudata was observed in the oldest mussels (9 yr) (Figs. $5 \& 6$ ). Although in the case of C. parvicaudata this decrease was not statistically proven (possibly due to the small sample size), visual observations showed a difference in infection between 8 and $9 \mathrm{yr}$ old individuals. In the case of $H$. elongata this pattern was highly significant. Maximal longevity of mussels in the White Sea intertidal populations does not exceed 10 yr (Savilov 1953, Sukhotin et al. 2003). The 9 yr old animals are already rare and $10 \mathrm{yr}$ old mussels are exceptional. Since $9 \mathrm{yr}$ old mussels are approaching the maximal lifespan, it is likely that the negative impact of parasitizing metacercariae may be greater in the oldest, weakest individuals. This may result in selective mortality of the most infected specimens due to the influence of unfavourable environmental factors (decreasing water salinity in spring, winter frosts on the intertidal zone, long-term air exposure etc.). Therefore, only the less-infected mussels remain alive. In addition, a decreased prevalence in the old mussels could be due to immune factors. Mussels in the research area were shown to be heterogeneous with regard to the degree of manifestation of non-specific defence mechanisms in response to penetration of cercariae of the studied trematode species (Gorbushin \& Levakin 2005). The population consists of individuals 
with different resistance to cercarial infection. It may be suggested that only the most resistant, and thus the most poorly infected, specimens live to older age (although no non-infected 8 or 9 yr old mussels were found).

Besides age, size also considerably influences infection intensity in mussels with metacercariae: among mussels of the same age, the highest IIn values are observed in larger individuals. Cercariae of the species studied enter the mantle cavity of the molluscan hosts passively in water currents via the inhalant siphon (Stunkard 1964, Loos-Frank 1967, Werding 1969, Lauckner 1983, de Montaudouin et al. 1998, Wegeberg et al. 1999, our observations). Therefore, the influence of host size upon IIn with metacercariae of Himasthla elongata and Cercaria parvicaudata may be mediated by the pumping rate of mussels. Pumping rate in bivalve mussels directly depends on the size of the animal (Winter 1978, Alimov 1981, Jørgensen 1990). Thus, increased pumping activity of mussels may increase the probability of their infection with trematode larvae.

As a corollary, in the host-parasite systems under consideration (mussels and metacercariae of Himasthla elongata and Cercaria parvicaudata), the infection indices of the molluscan hosts are determined by both their age and their size. Similar results were obtained by Bowers \& James (1967), who studied infection of the cockles Cardium edule by metacercariae of Meiogymnophallus minutus on the South Wales coast. A higher IIn in large juveniles of Cerastoderma edule compared to that in smaller ones was noted by de Montaudouin et al. (1998). A similar pattern may be characteristic of other host-parasite systems involving a long-living parasite, if the latter is not highly pathogenic to the host and if the probability of infection correlates positively with the host's size (in our case, this was mediated by pumping rate).

Acknowledgements. The project was funded by the Russian Foundation for Basic Research (grant N 04-04-49439) and INTAS (grant N 01-0210). We thank 3 anonymous reviewers for valuable comments on a draft of the manuscript. We also thank Dr. S. W. B. Irwin for English correction.

\section{LITERATURE CITED}

Alimov AF (1981) Functional ecology of freshwater bivalves. Nauka, Leningrad

Babkov AI (1998) Hydrological characteristics of the Chupa inlet of the White Sea. In: Babkov AI (ed) Hydrology of the White Sea. White Sea Biological Station, St Petersburg, p 50-67

Bartoli P (1974) Recherches sur les Gymnophallidae F. N. Morozov, 1955 (Digenea), parasites d'oiseaux des côtes de Camargue: systèmatique, biologie et ecologie. $\mathrm{PhD}$ thesis, Universitie d'Aix-Marseille
Bowers EA, James BL (1967) Studies on the morphology, ecology and life-cycle of Meiogymnophallus minutus (Cobbold, 1859), comb. nov. (Trematoda: Gymnophallidae). Parasitology 57:281-300

Chubrick GK (1966) Fauna and ecology of trematode larvae in molluscs of the Barents and White Seas. In: Polanski YI (ed) Life-cycles of parasitic worms from northern seas. Nauka, Leningrad, p 78-159

de Montaudouin X, Wegeberg AM, Jensen KT, Sauriau PG (1998) Infection characteristics of Himasthla elongata cercariae in cockles as a function of water current. Dis Aquat Org 34:63-70

Dogiel VA (1964) General parasitology. Oliver \& Boyd, Edinburgh

Dönges J (1969) Entwicklungs- und Lebensdauer von Metacercarien. Z Parasitenkd 31:340-366

Fjälling A, Kolsäter L, Thulin J (1980) En parasitologisk undersökning av vilda och oblade musslor, Mytilus edulis, i Tjärnö-området, Norra Bochuslän. Medd Havfiskelab Lysekil Hydrogr Avd Gteb 263:1-24

Galaktionov KV (2001) Parasites of common animals and animals of market value. In: Berger V, Dahle S (eds) White Sea, ecology and environment. Derzsavets, St. Petersburg, p 95-110

Gorbushin AM, Levakin IA (2005) In vitro encystment of cercariae of Himasthla elongata (Trematoda: Echinostomatidae). J Evol Biochem Physiol 41:343-349

James BL, Sannia A, Bowers EA (1977) Parasites of birds and shellfish. In: Nelson-Smith A, Bridges EM (eds) Problems of a small estuary. Proc Burry Inlet Symposium, Swansea, No. 1:1-16

Jørgensen CB (1990) Bivalve filter feeding: hydrodynamics, bioenergetics, physiology and ecology. Olsen \& Olsen, Fredensborg

Kennedy CR (1975) Ecological animal parasitology. Blackwell Scientific Publications, Oxford

Kulatchkova VG (1985) Parasites of blue mussels - the aquaculture object in the White Sea. In: Lukanin VV (ed) Investigation of the blue mussel of the White Sea. Zoological Institute, Leningrad, p 88-97

Kulatchkova VG (1987) Parasitological investigations in the White Sea. In: Berger VJ (ed) Hydrobiological and ichthyological investigations on the White Sea. Zoological Institute, Leningrad, p 107-131

Lauckner G (1971) Zur Trematodenfauna der Herzmusheln Cardium edule und Cardium lamarcki. Helgol Wiss Meeresunters 22:377-400

Lauckner G (1983) Diseases of Mollusca: Bivalvia. In: Kinne O (ed) Diseases of marine animals, Vol 2. Biologische Anstalt Helgoland, Hamburg, p 477-961

Lauckner G (1987) Ecological effects of larval trematode infestation on littoral marine invertebrate populations. Int J Parasitol 17:391-398

Loos-Frank B (1967) Experimentelle Untersuchungen über Bau, Entwicklungen und Systematik der Himasthline (Trematoda, Echinostomatidae) des Nordenseeraumes. Z Parasitenkd 28:299-351

Lukanin VV (1985) Distribution of mussels Mytilus edulis in the White sea. In: Lukanin VV (ed) Investigation of the mussel of the White sea. Zoological Institute, Leningrad, p 45-58

Savilov AI (1953) Growth and its variability in the White Sea invertebrates Mytilus edulis, Mya arenaria and Balanus balanoides. Part I. Mytilus edulis in the White Sea. Proc Inst Oceanol Acad Sci USSR 7:198-258

Stunkard HW (1964) Studies on the trematode genus Renicola: observations on the life history, specificity and sys- 
tematic position. Biol Bull 126:468-489

Sukhotin AA (1993) The investigations of mussel mariculture in the White Sea, Vol 253. Zoological Institute, St. Petersburg

Sukhotin AA, Maximovich NV (1994) Variability of growth rate in Mytilus edulis L. from the Chupa Inlet (the White Sea). J Exp Mar Biol Ecol 176:15-26

Sukhotin AA, Lajus DL, Lesin PA (2003) Influence of age and size on pumping activity and stresss resistance in the marine bivalve Mytilus edulis L. J Exp Mar Biol Ecol 284:129-144

Underwood AJ (1981) Techniques of analysis of variance in experimental marine biology and ecology. Oceanogr Mar Biol Annu Rev 19:513-605

Editorial responsibility: Albert Sparks, Seattle, Washington, USA
Wegeberg AM, de Montaudoin X, Jensen KT (1999) Effect of intermediate host size (Cerastoderma edule) on infectivity of cercariae of three Himasthla species (Echinostomatidae, Trematoda). J Exp Mar Biol Ecol 238:259-269

Werding B (1969) Morphologie, Entwicklung und Ökologie digener Trematoden-larven der Strandschnecke, Littorina littorea. Mar Biol 3:306-333

Winter JE (1978) A critical review on some aspects of filter feeding in lamellibranchiate bivalves. Haliotis 7:71-87

Zelikman EA (1966) Some ecological and parasitological links in the littoral zone of the northern part of the Kandalaksha Bay. In: Polanski YI (ed) Life-cycles of parasitic worms from northern seas. Nauka, Leningrad, p 7-77

Submitted: February 23, 2005; Accepted: March 5, 2006 Proofs received from author(s): June 29, 2006 